\title{
Why Demotion of Older Workers is a No-Go Area for Managers*
}

\author{
Hendrik P. van Dalen ${ }^{a, c}$ and Kène Henkens ${ }^{a, b, d}$
}

(a) Netherlands Interdisciplinary Demographic Institute (NIDI)

P.O. Box 11650

NL-2502 AR The Hague

The Netherlands

Email: dalen@ nidi.nl

(b) University of Groningen

University Medical Center Groningen (UMCG)

P.O. Box 72

NL-9700 AB Groningen

The Netherlands

(c) Tilburg University

Tilburg School of Economics and Management (TISEM), and TIAS Business School

P.O. Box 90153

NL-5000 LE Tilburg

The Netherlands

(d) University of Amsterdam

Department of Sociology and Anthropology

Oudezijds Achterburgwal 185

1012 DK Amsterdam

The Netherlands

Email: henkens@nidi.nl

NOTE: this is a preprint version of the paper published in The International Journal of Human Resource Management, published online October 2, 2016, DOI:

http://dx.doi.org/10.1080/09585192.2016.1239214

Version: 8 July 2016

Keywords: older workers, demotion, productivity, managers, vignette study

JEL codes: M51, M54, J62 


\begin{abstract}
:
Demotion - the reduction of an employee's rank and salary - is often mentioned by managers and policy makers as a means of increasing the employability of older workers in an ageing labour force. However, so far in practice demotion is rarely applied. This paper is the first empirical investigation of how managers perceive demotion as an instrument of human resource management. By means of a survey and a vignette study among managers in the Netherlands ( $\mathrm{N}$ =355) we examine whether managers consider demotion of poorly performing older workers a fair solution. Three contributions stand out. First, based on attribution theory we find support for the hypothesis that managers judge demotion to be fair in those cases where deterioration in task performance is caused by controllable factors (such as work motivation) and unfair when the causes are uncontrollable (such as age). Second, the expectations of managers about the organization wide consequences of introducing demotion as a human resource policy play a significant role in considering demotion. Most managers perceive negative organizational externalities (e.g., decrease in loyalty and motivation of staff) to arise when introducing demotion and are reluctant to apply demotion in practice. Three, positive (negative) beliefs about the hard skills - e.g. creativity, willingness to learn, flexibility - of older workers make demotion less (respectively more) likely.
\end{abstract}

* Comments by Douglas Hershey, Tinka van Vuuren, Mo Wang, Arjen van Witteloostuijn and participants of seminars of the Catholic University of Leuven, at the University of Copenhagen, and at the European Population Conference in Budapest and three anonymous referees of this journal are gratefully acknowledged. Part of the paper was written during a stay at the Netherlands Institute for Advanced Studies (NIAS), Wassenaar. In this paper we make use of data of the LISS (Longitudinal Internet Studies for the Social sciences) panel administered by CentERdata (Tilburg University, The Netherlands). 


\section{Introduction}

Demotion, or the reduction of an employee's rank and salary, is a topic that receives cursory attention in the economics and management literature. Internationally, many employers re still grappling with the aftermath of the Global Financial Crisis of 2008 as well as the consequences of an ageing labour market, and demotion is expected to be one of the instruments that might make adaption possible. Well known management and economic textbooks (Milgrom and Roberts, 1992, Lazear, 1998) focus primarily on promotion as an incentive mechanism for employees, and the term 'demotion' is either missing, relegated to footnotes, or referred to merely as a suggestion for future research (Lazear, 1995). Perhaps because of this lack of attention, some scholars wonder whether demotion is in fact a 'four-letter word' (Kohl and Stephens, 1990). Others (Carson and Carson, 2007) remark that demotion 'might well be considered management's "dirty little secret", the secret being that for some decades there have been pleas to examine the topic systematically, yet there remains little empirical insight into questions of under what circumstances demotion might be considered by managers or how demotion affects either organizations or employees. The present study is the first empirical investigation into the question of the extent to which the demotion of workers is considered by managers as part of human resources (HR) policy. We examine this question through a combination of a survey and a vignette study with managers in order to uncover the main driving forces behind their choice of whether to use demotion for employees who perform poorly.

There could be a number of reasons why demotion is still such a rare phenomenon. First, the importance of reputation and self-selection in the labour market can be so strong and pervasive that employees do not allow their careers to be tarnished by demotion, preferring to resign instead. For instance, MacLeod and Malcomson (1988) claim that promotion structures based on performance, which are a dominant feature of the incentive structure of large organizations, are maintained 'by ensuring that it is optimal for employees to quit rather than accept demotion with their present employer' (p. 834). The reputations of employees play a major role in this model because demotion is felt to signal that the candidate underperformed, and rather than face this possible decline in reputation the employee will opt to leave the firm. While this model may apply to younger workers, older workers are better protected and 
experience far greater difficulty finding work than younger workers, and are therefore less likely to leave a firm voluntarily (Gielen and van Ours, 2006).

A second reason why demotion is not often applied could be because it can involve high transaction costs. (Van Dalen, Henkens and Schippers, 2010a) show that within most organizations it is common practice to permit poorly performing older employees to remain in post, where younger workers who perform badly are dismissed. A possible explanation for this resistance to demotion is that managers suspect it causes tension not only among those who are demoted ('demotees') who experience the stigma of failure (Carson and Carson, 2007), but also among colleagues who perceive that implicit contracts - promises of upward wage growth as a result of seniority and/or a series of promotions - are not honoured by their organization. If the organization regularly uses demotion as an instrument to address divergences between pay and performance, this may be counter-productive. Ederer and Patacconi (2010) suggest that an incentive structure that makes explicit not only the winners in a tournament but also the losers can lead to less effort being made by participants, especially when losing involves a loss of status. When managers consider changes to incentive structures, they must therefore take account of the possible drawbacks of demotion in terms of its effects as a possible disincentive for staff. This includes the possibility that demotion will be viewed as a breach of contract even by staff who are not affected directly by the demotion, and will therefore have a negative impact on the morale, performance, and productivity of staff at the organization more generally. Demotion may therefore remain an example of 'blackboard economics': in theory demotion is an obvious solution when employees do not perform according to the terms of their contract, but in practice it is a complex decision with possible unforeseen repercussions.

The present paper contributes to the existing empirical literature in organization studies, labour economics, and HR management in three main ways. First, it breaks new ground by offering the first empirical investigation of how managers assess demotion as an instrument of HR policy. We do so by applying and extending attribution theory to this specific domain and to determine whether a manager will consider demotion appropriate for older workers when they show a decline in performance. As such, our findings complement those of researchers who use attribution theory to focus on HR strategies (Harvey, Madison, Martinko, Crook and Crook, 2014). By integrating insights from economics, psychology, and management this paper 
provides a comprehensive study on demotion by combining factors which relate to the individual worker who does not perform up to organizational standards, as well as a group of factors relating to the characteristics of the manager actually contemplating demotion.

The second contribution relates to measuring the influence of stereotypical views of managers in making assessments about older workers. Stereotypes are known to play a pervasive role in HR practices, such as hiring and retention of older workers (Chui, Chan, Snape and Redman, 2001, Posthuma and Campion, 2009), and a priori one would expect stereotypical beliefs about their productive roles to be of some importance in considering demotion for individual workers. In our analysis we stress and measure the importance of so-called soft versus hard skills or qualities of older workers (cf. Van Dalen, Henkens and Schippers (2010b)). In our analysis soft qualities refer to elements of task performance such as social skills, reliability, management and commitment. Hard qualities include in our setup creative skills, mental and physical capacity to deal with workload, willingness to learn new skills and to adapt to new technology, and flexibility.

Third, the present paper contributes the literature on the economics of human resources by highlighting the importance of what we denote as organizational externalities: organization wide consequences of an individual decision. In other words, these externalities measure how a specific HR management measure affects the organizational climate of an organization, at least as perceived by managers. And as our analysis suggests, one of the most prominent explanatory factors for refraining from demotion are the expectations of managers about the organizational externalities that might arise from the introduction of demotion as an HR policy in an organization. Hence, not only the demotee can be affected by such a decision (Carson and Carson, 2007) but also the colleagues of the demotee and the organization at large. The reason why this effect may apply is that such a decision signals to the organization at large how management will deal with poor performance. Different managers inevitably make different assessments of the wider organizational consequences of introducing demotion into HR policy because the contexts of their firms differ. These expected externalities may make them either more reluctant or more likely to apply demotion in individual cases. Externalities are generally assumed to be present where market participants fail to take account of the wider organizational effects that their individual actions may bring about. This paper aims to explore whether 
managers consider what the organizational external effects of their actions may be, and how this in turn affects their decisions or evaluations. Incorporating employee and employer characteristics in our explanatory framework offers not only the possibility to elicit the views of managers on the desirability of demotion in the cases of specific employees, it also uncovers the extent to which the manager takes the organizational externalities of demotion into account.

By combining survey data with a vignette study we were able to obtain a broader perspective on demotion. Vignette studies generally help to elicit preferences or evaluations that are hard to capture by direct observation. Our vignette study and survey were carried out among managers $(\mathrm{N}=355)$ in the Netherlands in April 2013. But before we present the design and empirical results of our study, we present some background evidence on the use of demotion among European employers, and offer an argument to show why the Netherlands is such an interesting case for the study of demotion.

\section{Demotion as a human resource policy instrument}

Demotion is often shrouded in issues of age discrimination and unfair dismissal, which hampers the recording of demotion in official statistics. We nevertheless present some figures from a European wide survey of 4,000 employers, which contains information on demotion (Henkens and Schippers, 2012). Employers were asked to what extent they apply a certain instrument in their HR policy; where they did not apply a specific instrument, they were asked whether they would consider including it in their policy in the near future. Demotion (the lowering of rank and wage) was one of the instruments included and Figure 1 depicts the outcomes for the various countries in the survey.

Demotion is not often encountered in the HR policies of European employers (Van Dalen, Henkens and Schippers, 2009b, Josten and Schalk, 2010), and this is in line with statistical evidence for the US also (Baker, Gibbs and Holmstrom, 1994, Gibbons and Waldman, 1999, Bowlus and Robin, 2004, Gibbs and Hendricks, 2004). In all the countries listed in Figure 1, between 1 and $4 \%$ of employers applied this instrument in their HR policies. Denmark is the exception, with $10 \%$ of Danish employers including demotion in their policies. However, consideration of demotion is much more prevalent, and if this is included it may be said that 
demotion is either applied or considered by a sizable number (ranging between $20 \%$ in Sweden and $40 \%$ in The Netherlands) of employers in Germany, Poland, Sweden, Denmark, and the Netherlands.

Figure 1: Percentage of organizations applying and considering demotion in Europe, 2009

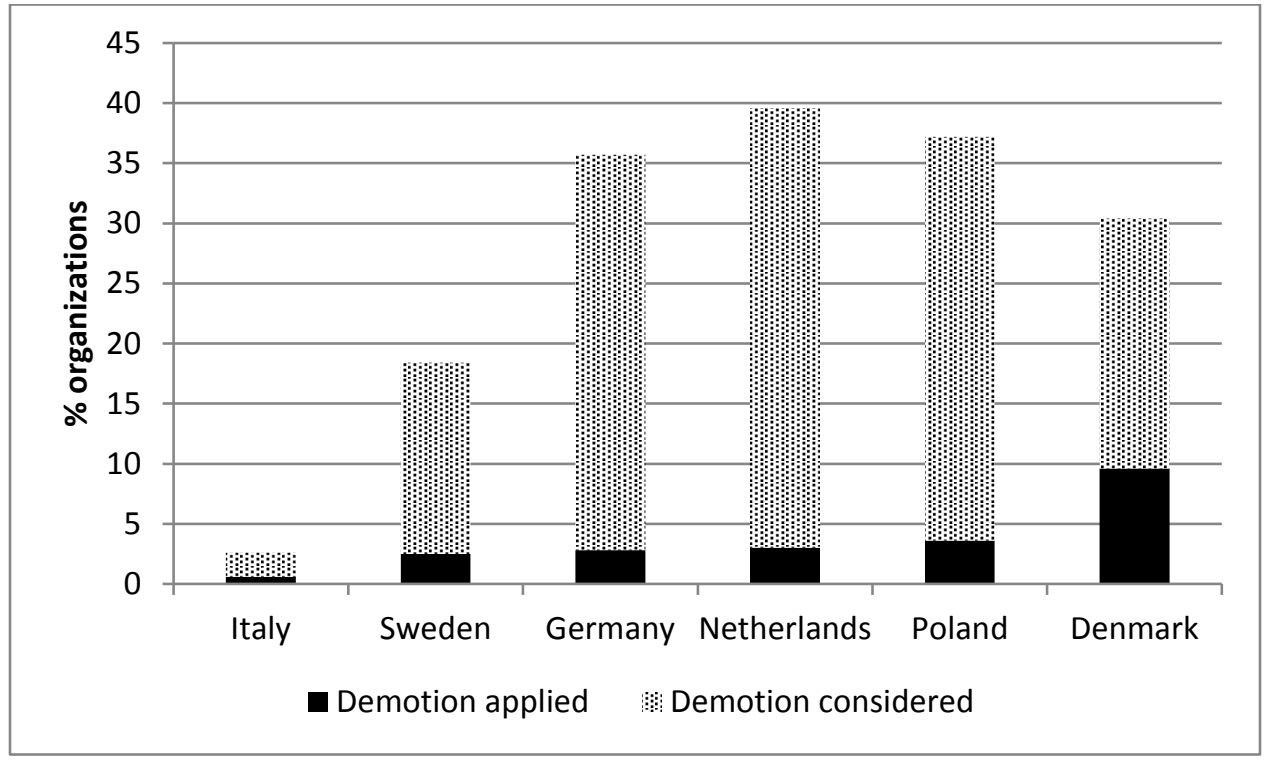

Source: Activating Senior Potential in Ageing Europe (ASPA), http://www.aspa-eu.com/

The only outlier in this picture is Italy, which is not that surprising because over a broad range of measures, Italian employers appear relatively unconcerned about their ageing work force (Conen, van Dalen and Henkens, 2012). The fact that Danish employers are more likely to apply demotion than other European employers (Figure 1) might be related to by the fact that the Danish focus on security in employment and income combined with labour market flexibility. The idea behind this so-called 'flexicurity' is that by combining flexibility and social security, both employers and workers are more willing to take risks in the labour market. By increasing security in connection with, for instance, job change, workers are encouraged to become more mobile in the labour market (Andersen, 2012). Functional flexibility and pay-level flexibility are a logical outcome of this model of employment protection and these in-built flexibilities in the labour market facilitate the consideration and application of demotion. 
Nevertheless there are several reasons why demotion may increasingly be considered as a policy option by European employers. The presence of seniority based wage systems in Europe is one reason (Deelen, 2012). The seniority principle implies that that during the first phase of workers' careers their earnings are lower than their productivity and during the second phase their earnings are higher than their productivity. According to Thurow (1975) the prospect of a gradual rise in wage income functions as an incentive for employees to continue working for their employer and invest in firm-specific knowledge. Lazear (1979) stressed that this implicit contract is bound to be unsustainable if workers work beyond the age at which the net present value (over the working life) of wages exceeds that of the net present value of production of the employee in question. Therefore, employers will either opt for mandatory retirement schedules or the use of private pension schemes which penalize continued employment beyond a certain age. The trouble with these types of implicit contracts is that the sustainability of the contract is negatively affected by the ageing of the workforce (Lazear, 1990). Seniority wages imply a heavy wage burden for employers. Whereas organisations in some countries in the past could thrive because of a relatively young age structure thereby also enjoying a 'demographic dividend' (cf. Bloom, Boersch-Supan, McGee and Seike (2011)), in contemporary times organizations will have to face an ageing work force and bear the costs of a 'demographic hangover' if nothing changes and workforce ageing takes its course.

A second reason why many European employers consider the introduction of demotion is connected to the existence of strong employment protection legislation in Europe, which limits the ability of employers to make changes to their labour market demand in the face of adverse structural changes. This means that most of the changes in labour demand are absorbed through the dismissal of employees with short-term contracts, and by and large older workers are retained.

The Dutch case is of significant interest because it combines all the above elements. Not only do employers in the Netherlands have to deal with older workers who often have permanent contracts and are well protected by employment legislation, but until now wage systems in the Netherlands have been based primarily on seniority. Furthermore recent pension reforms have put an end to the Dutch early retirement culture (OECD, 2014), which is reflected in a steep increase in the participation of older workers in the workforce in the past ten years. In short, 
employers in the Netherlands are obliged to consider and make use of the potential of older workers. They cannot, as in the recent past, use early retirement packages as an alternative dismissal route for older workers. Dutch employer organizations are lobbying to make demotion standard in all wage contracts and see this as a cornerstone of dealing with an ageing work force. Of course, the question remains whether those who manage actual decisions are willing to consider demotion and put theory into practice. The gap that exists between the consideration and the application of demotion in European countries is intriguing, and the case in the Netherlands is in that respect worthy of in-depth examination. To provide a framework for our empirical study we first provide an overview of what the theories have to offer on the issue of demotion.

\section{Theoretical background}

Two intertwined strands of literature help to understand the evaluations and decisions of employers with respect to demotion. The first strand of literature can be traced to organizational psychology (Erber and Long, 2006, Cox and Beier, 2014, Harvey et al., 2014), where attribution theory is of considerable importance to our understanding of behaviour and organizational outcomes. In the present case we hypothesize that the use of demotion depends on the ways in which managers attribute the underlying causes of poor performance.

The second strand is found partly in the domain of economics where it has become common to consider the possibility that individual actions have external effects, either positive or negative. We examine whether managers take externalities into account within their organization in considering an individual action: the demotion of a poorly performing employee. We assume that the effects of demotion on the behaviour of third parties, such as co-workers and potential employees, come into play when managers make individual decisions or evaluations. Managers may be more supportive of demotion when they expect it to generate positive outcomes for the firm as a whole, but less supportive of demotion when they expect negative consequences. We term these effects the expected externalities of demotion.

\section{Attributing poor performance}

In the case of demotion, when managers are faced with an employee who displays poor performance (poor productivity, sloppy work), it is in the manager's interest to trace the cause of 
this poor performance. Often, managers use a set of informational indicators or outcomes to try to attribute the poor performance to certain underlying causes. In the burgeoning social psychological literature several attributional dimensions are identified (Weiner, 1993, Weiner, 1995) that are of importance in understanding organizational behaviour: the locus of causality whether the cause is perceived to be an aspect of the individual rather than a specific situation; stability - whether the cause is perceived to occur consistently over time or not; and controllability - whether a person is perceived to have control over the cause. The locus of causality and controllability have much in common. When an internal attribution is made to controllable causes, the perceived cause of the behaviour lies within the person, meaning that the person is in control over that behaviour and is responsible for that behaviour. For example, in our study low effort or motivation may be attributed to controllable internal factors. When an external attribution is made, the cause of the behaviour is assigned to uncontrollable factors, such as bad luck or some other external reason. An example of external or uncontrollable attribution in the case of demotion might be poor performance due to certain health problems. But in practice the perception of causes may and can differ. For instance, the health status of an individual or the existence of problems at home are factors over which an individual has only limited control. These sorts of factors are nonetheless of interest and because of their mixed character we expect them to carry less weight in considerations of demotion than clearly controllable factors.

The importance of the process of attribution in making decisions was demonstrated by Mitchell and Wood (1980) and Wood and Mitchell (1981), who carried out experiments in a number of hospitals to study how supervisors attributed poor performance to internal and external causes and how their responses differed according to their attribution. In general, they found that punitive measures are more likely when poor performance is attributed to internal and controllable causes, namely employee characteristics or behaviours such as lack of effort, motivation, or ability. These dimensions are deemed relevant when supervisors decide whether or not an employee should be demoted. When the cause of poor performance is perceived to be beyond the control of the employee, demotion is hypothesized to be less likely than in those cases where poor performance is attributed to controllable causes such as lack of motivation. 
To test the attribution hypothesis we specifically selected five different dimensions that have been empirically shown to be linked to the performance of employees and which vary with respect to controllability. These dimensions include: work motivation, age, willingness to train, health status, and whether an employee is having problems at home. In general it is well documented that work motivation - whether intrinsically or extrinsically based - is a clear determinant of performance (see meta study by Cerasoli, Nicklin and Ford (2014)). The willingness of older workers to engage in training is also documented as an indicator of performance as it generally signals that such workers are willing to adopt new roles and acquire new skills (Van Vianen, Dalhoeven and De Pater, 2011). Moreover, having received training is generally linked to productivity growth of employees (Bartel, 1994, Black and Lynch, 1996). Health and problems at home are seen in this context as performance factors that may be perceived to be externally located. The health of employees is generally perceived to be a clear determinant of performance (Van den Heuvel, Geuskens, Hooftman, Koppes and Van den Bossche, 2010) whereas "having problems at home" is an example of the family-work conflicts that are demonstrated as having a negative impact on performance (Demerouti, Bakker and Voydanoff, 2010, Nohe, Michel and Sonntag, 2014). Age is also included to see whether within the group of older workers one can detect whether age is attributed as a significant cause of poor performance. In the literature it is known that when older and younger workers show equal poor performance, the poor performance of older workers is attributed to age-related decline, while a similar poor performance among the young is attributed to lack motivation (Dedrick and Dobbins, 1991, Erber and Long, 2006, Cox and Beier, 2014) . Because we restrict our attention to older workers (45-60 years) such a test is not possible, but it may offer some a test to see whether a possible attributed age-related decline impacts the decision to demote. If the previous findings in the literature are robust, age should not have an effect within the group of older workers.

H1: Attribution hypothesis: Managers will be more in favour of demotion for a poorly performing older worker who has low work motivation or low willingness to be trained (controllable factors), compared to a poorly performing older worker in poor health or with problems at home (uncontrollable factors). 


\section{Organizational externalities of demotion}

The perceived organizational externalities of demotion involve the perceived costs and benefits of demotion for the wider organization. When a specific employee is performing poorly to the extent that their manager considers demotion, the employer probably sees the poor performance as a breach of contract on the part of the poorly performing worker. However, the incumbent personnel staff may view demotion as a breach of contract on the part of the employer because demotion was not part of the incentive structure when they entered the contract with the employer. Employees may perceive their relationship with their employer as a 'psychological contract', which has been referred to as 'employees' perceptions of what they owe to their employers and what their employers owe to them' (Robinson, 1996). When their trust is breached this may trigger reciprocal actions from employees. We assume that employers have expectations about the behavioural response of their staff when demotion becomes part of HRpolicy. If employees perceive the change in the incentive structure to be unfair, they may respond negatively to such a decision by management (Bosse, Phillips and Harrison, 2009). However, it cannot be ruled out that managers might expect benign effects to result from demotion because employees could also respond in a positive way. Ederer and Patacconi (2010) are among the few to have analysed this issue in a theoretical model of demotion and promotion. Demotion could trigger greater effort, but if one considers status issues and assumes that employees also care about their relative standing in an organization, the situation changes. Demotion penalizes underperformance and thereby not only makes the spread in wages larger but also makes the 'losers' visible. When status is a driving force behind work effort, a demotion has negative consequences as it generates less effort compared to situation where only promotions are possible.

When gauging the effects of demotion these incentive and disincentive effects are key to understanding the decision making process of employers when they consider demotion. In an environment in which demotion is rare, one would expect that demotion may induce nonproductive behaviour in employees, such as showing less loyalty to management, becoming less motivated to work, and sabotaging organizational procedures (Ambrose, Seabright and Schminke, 2002). On the other hand demotion may also generate productive behaviour such as an increased willingness to participate in training. We assume that managers take these expected 
responses into account in deciding on the demotion of individual employees. On the basis of this short overview we formulate our organizational externalities hypothesis:

H2: Organizational externalities hypothesis: Managers will be less likely to favour demotion of a poorly performing older worker the more negative the perceived organizational externalities of demotion are for the organization as a whole.

\section{Stereotypical beliefs}

Finally, the reasons for considering an older worker for demotion may be deeply rooted in the beliefs of a manager about the capabilities of older workers in general. Well-documented evidence suggests that managers often hold stereotypical views about older workers. They often see older workers as inflexible, unwilling (or unable) to adapt to a changing work environment, and less productive than their younger colleagues. However, these studies also confirm that older workers are valued for their trustworthiness, specific knowledge, and interpersonal skills (Lee and Clemons, 1985, Finkelstein and Burke, 1998, Taylor and Walker, 1998, Loretto, Duncan and White, 2000, Chui et al., 2001, McCann and Giles, 2003, Munnell and Sass, 2008). Van Dalen et al. (2010b) have captured this dual aspect of stereotypes regarding the productivity of older workers. They showed that employers' attitudes towards older workers reflect two dimensions: hard and soft skills. Soft skills are defined as qualities that can be characterized as 'organizational citizenship behaviour' - pro-social behaviour that is not job-specific but which supports the broader organizational environment in which jobs are performed ( $\mathrm{Ng}$ and Feldman, 2008, Van Dalen et al., 2010b). Hard skills, on the contrary, reflect mental and physical capacity, willingness to learn new skills and to adapt to new technologies, and flexibility. An important aspect of stereotypes is that prevailing views may affect managers' discriminatory attitudes and behaviour (Chui et al., 2001). We therefore posit a third hypothesis:

H3: Older worker stereotype hypothesis : Managers will be more in favour of demotion of a poorly performing older worker, the more negative the stereotypical views they have toward the productive skills of older workers. 


\section{Data and methods}

To answer the foregoing research questions, a research process consisting of a combination of survey research and a vignette study was designed. ${ }^{1}$ The survey was conducted to gather information about the expectations of managers contemplating the decision to demote. The vignettes were designed to see how managers evaluate particular cases of older employees who perform poorly. We collected our data by accessing the sample of the Longitudinal Internet Studies for the Social Sciences (LISS) of Tilburg University (http://www.lissdata.nl/lissdata/). LISS is an Internet panel that consists of approximately 6,500 individuals. All individuals are selected on the basis of a true probability sample of households drawn from the population register by Statistics Netherlands. For the current study we randomly selected a small sample of managers $(\mathrm{N}=355)$. The data were collected in April 2013 and the response rate was 84\%. Managers in the LISS panel were identified based on their answers to the questions regarding whether they supervise others in their current occupation and whether they had experience of hiring personnel in the past 10 years. A minority of managers were female (35\%), and the mean age of managers was 47.7 (range 24-67 years, $\mathrm{SD}=10.3$ ).

A vignette experiment combines survey questions with experimental methods, and is considered especially suitable as a method to uncover the underlying structure of human judgments in social contexts (Rossi and Anderson, 1982b, Wallander, 2009). The usual procedure in this type of experiment is that participants see a vignette that contains descriptive information about a situation, after which they are prompted for their judgment on it. Vignette studies or conjoint analyses are widely used in the social sciences (Green and Srinivasan, 1978, Cattin and Wittink, 1982, Finch, 1987, Kapteyn, Smith and Van Soest, 2007) because they shed light on the preference structures of people who evaluate a situation or make decisions. The values on vignette factors are randomized, so that each combination of values is equally likely (an example of a random vignette is presented in the Appendix). An important requirement in designing vignettes is that the number of characteristics included in the vignettes should be limited, because participants are expected to have difficulty in processing large amounts of information and could face difficulties in visualizing a hypothetical person or the specific context

\footnotetext{
${ }^{1}$ Vignette studies are also known as conjoint analysis or factorial studies and are closely related to so-called 'policy capturing studies' (see e.g., Rotundo et al., 2002)
} 
if too many factors are involved (Rossi and Anderson, 1982a). Vignette dimensions are orthogonal, which offers the opportunity to separate the effects of variables that are often correlated in practice, avoiding multicollinearity (Di Stasio, 2013). It is common to ask participants to rate multiple vignettes in order to increase the reliability of the estimates and to enable assessment of both between-subject and within-subject effects (Wallander, 2009).

\section{Vignettes}

In a vignette design the unit of analysis is the vignette, a hypothetical situation, to which participants respond thereby revealing their perceptions, preferences, values or social norms. For the current study, the introduction to each vignette provided managers with information that the employee under review was performing poorly with respect to the tasks of their job. For each vignette managers were asked "How fair would it be to consider demotion for this specific employee? (Answer categories were on a 10-point scale, ranging from 0 (very unfair) to 10 (very fair)). To test the hypothesis 1 about the attribution process the vignettes contained some variables that lay within the control of the individual, such as willingness to participate in training, and work motivation, and some variables that lay beyond the employee's control to a varying degree, such as age which is deemed an uncontrollable factor, to factors such as health, and problems at home which may be perceived as weakly controllable (see theory section for factors included)

Finally, to make the vignettes more realistic we control for two aspects: (1) the relative wage level of the employee in question - measured by whether the wage of the employee is either higher or lower than that of colleagues at the same job level - and (2) the financial health of the organization.

In summary, the seven vignette characteristics were: (1) age of the employee; (2) employee's work motivation; (3) health status; (4) willingness to participate in training; (5) problems at home; and (6) the wage level of the worker in question relative to colleagues at the same job level: (7) the financial situation of the firm. In Table 1 we provide an overview of the various values for each vignette item. 
Table 1: Organizational contexts and employee attributes in the vignette

\begin{tabular}{|c|c|}
\hline Item & tegories \\
\hline \multicolumn{2}{|l|}{ Organization } \\
\hline $\begin{array}{l}\text { Financial position of the } \\
\text { organization }\end{array}$ & $\begin{array}{ll}\text { - } & \text { Financially sound } \\
\text { - } & \text { Financially vulnerable } \\
\text { - } & \text { In financial trouble }\end{array}$ \\
\hline \multicolumn{2}{|l|}{ Employee } \\
\hline Age & $\begin{array}{l}\text { - } 45 \text { years } \\
\text { - } 50 \text { years } \\
\text { - } 55 \text { years } \\
\text { - } 60 \text { years }\end{array}$ \\
\hline Work motivation & $\begin{array}{l}\text { - } \text { High } \\
\text { - Low }\end{array}$ \\
\hline $\begin{array}{l}\text { Willingness to participate in } \\
\text { training }\end{array}$ & $\begin{array}{ll}\text { - } & \text { High } \\
\text { - } & \text { Low }\end{array}$ \\
\hline Health status & $\begin{array}{l}\text { - In good health } \\
\text { - Not so healthy }\end{array}$ \\
\hline Problems at home & $\begin{array}{ll}\text { - } & \text { Yes } \\
\text { - } & \text { No }\end{array}$ \\
\hline $\begin{array}{l}\text { Wage level in comparison to } \\
\text { colleagues with the same } \\
\text { function }\end{array}$ & $\begin{array}{ll} & \text { Higher than comparable colleagues } \\
\text { - } & \text { Lower than comparable colleagues }\end{array}$ \\
\hline
\end{tabular}

Given all possible combinations of the variables and their respective categories, a set of 384 unique vignettes was created (i.e. $3 \times 4 \times 2 \times 2 \times 2 \times 2 \times 2$ ), and these vignettes were randomly allocated among the managers. None of the vignettes contained an impossible combination of the factors. For an example of a vignette used in the study, see Figure A1 in the Appendix. With N=355 managers rating five vignettes each, a total of 1,775 vignettes were rated, and the average number of rates per unique vignette was 4.6. Each respondent was asked to rate five vignettes in order to prevent cognitive overload and fatigue effects in making the evaluations (Sauer, Auspurg, Hinz and Liebig, 2011). 


\section{Organizational Externalities}

To measure perceptions of the negative or positive organizational external effects of demotion (hypothesis 2) we asked all managers to assess how staff in general would respond to demotion being introduced into HR policy within the organization. The exact question on which the scale was based was: "What do you expect to be the consequences of making demotion an integral part of the human resources policy in your organization?" They were asked to evaluate these consequences for the following five issues:

- Loyalty of the staff towards the management of the organisation

- Work motivation of the staff

- The ability of the organization to attract new work staff

- Willingness of staff to undertake training

- Solidarity between younger and older staff

The answer categories were 1 = will increase strongly; 2 = will increase somewhat; $3=$ no change; 4 = will decrease somewhat; and $5=$ will decrease strongly. We constructed a 5-point scale variable 'Expected externalities', and the internal consistency reliability was assessed using Cronbach's alpha. The Cronbach's alpha statistic was 0.80 , which suggests that the scale is a reliable summary of the underlying information in the separate items.

\section{Beliefs about the skills of older workers}

In order to assess the extent to which the managers held stereotypical views of older workers (hypothesis 3), they were each given a list of 11 characteristics of older workers. We asked: "To what extent do the following characteristics apply to workers in general, aged 50 or older?" The characteristics presented were: flexibility, social skills, commitment to the organization, creativity, management skills, reliability, willingness to learn, physical capacity, resistance to stress, new technological skills. The answer categories were (1) hardly, (2) somewhat, (3) strongly, and (4) very strongly. 
Table 2: Descriptive statistics of vignette characteristics and background variables

\begin{tabular}{|c|c|c|}
\hline \multicolumn{3}{|l|}{ Vignette items } \\
\hline Dependent variable & Mean & s.d. \\
\hline Fairness of demotion ${ }^{a}$ & 4.81 & 2.17 \\
\hline \multicolumn{3}{|l|}{ Independent variables } \\
\hline \multicolumn{3}{|l|}{ Financial position firm (sound = 0) } \\
\hline Vulnerable & 0.36 & 0.48 \\
\hline In financial trouble & 0.31 & 0.46 \\
\hline \multicolumn{3}{|l|}{ Characteristics of employee } \\
\hline \multicolumn{3}{|l|}{ Work motivation $($ high $=0$ ) } \\
\hline Low & 0.52 & 0.50 \\
\hline \multicolumn{3}{|l|}{ Willingness to train $($ high $=0)$} \\
\hline Low & 0.53 & 0.50 \\
\hline \multicolumn{3}{|l|}{ Age $(45$ years $=0)$} \\
\hline 50 years & 0.25 & 0.43 \\
\hline 55 years & 0.25 & 0.43 \\
\hline 60 years & 0.25 & 0.43 \\
\hline \multicolumn{3}{|l|}{ Health $(\operatorname{good}=0)$} \\
\hline Not so healthy & 0.52 & 0.50 \\
\hline \multicolumn{3}{|l|}{ Problems at home $($ no $=0)$} \\
\hline Yes & 0.54 & 0.50 \\
\hline \multicolumn{3}{|l|}{ Wage level compared to colleagues $($ higher $=0$ ) } \\
\hline Lower & 0.50 & 0.50 \\
\hline $\mathbf{N}$ vignettes $=$ & & \\
\hline \multicolumn{3}{|l|}{ Characteristics of manager } \\
\hline Age (in years) & 47.70 & 10.32 \\
\hline Sex $($ male $=0)$ & 0.35 & 0.48 \\
\hline Owner-manager $($ employee $=0)$ & 0.11 & 0.31 \\
\hline Perception soft skills older workers (4-point scale) ${ }^{c}$ & 2.82 & 0.47 \\
\hline Perception hard skills older workers (4-point scale) ${ }^{d}$ & 2.14 & 0.44 \\
\hline Expected externalities demotion (5-point scale) ${ }^{\text {b }}$ & 3.25 & 0.70 \\
\hline $\mathrm{N}$ managers $=$ & & \\
\hline
\end{tabular}

(a) Fairness is assessed by the answer given to the question: "To what extent would you find a demotion in this particular case fair?" (0) very unfair to (10) very fair.

(b) Scale variable based on expected consequences of demotion on a five-point scale with respect to (1) loyalty of personnel to management; (2) motivation to work; (3) ability to attract new personnel; (4) willingness to undertake training; (5) solidarity between younger and older staff members. The scale reliability coefficient (Cronbach alpha) is 0.80 . Scale $1=$ strong increase to $5=$ strong decrease.

(c) Soft skills were based on a four-point scale for the following separate skills of employees of 50 years and older: (1) social skills, (2) management skills; (3) loyalty; and (4) reliability. The scale reliability coefficient (Cronbach alpha) is 0.74 . Scale $1=$ not/limited applicable to $4=$ very applicable.

(d) Hard skills were based on a four-point scale for the following separate skills of employees of 50 years and older: (1) flexibility, (2) creativity; (3) willingness to train; (4) physical capacity, (5) mental capacity; (6) new technology skills. The scale reliability coefficient (Cronbach alpha) is 0.78 . Scale $1=$ not/limited applicable to $4=$ very applicable. 
Based on a confirmatory factor analysis, two factors were selected, which were defined as soft and hard skills ${ }^{2}$ (see for an elaborate discussion of the scale development (Van Dalen, Henkens and Schippers, 2009a, Van Dalen et al., 2010b) ). The soft skills scale consisted of the following four items: social skills, commitment to organization, management skills, and reliability (Cronbach's alpha $=0.72$ ). The hard skills scale was based on these items: creativity, flexibility, willingness to learn, physical capacity, resistance to stress, and new technological skills (Cronbach's alpha $=0.78$ ). The prime working age in the Netherlands is between 20 and 65. Older workers in our survey were defined as being 50 years and older. The age cut-off of 50 years was chosen because most government (subsidy) programs aimed at stimulating demand for older workers, as well as HR policies within organizations, refer to older workers as 50 years of age and older (cf. OECD (2006)).

Table 2 offers an overview of all the relevant variables used in the statistical analysis, distinguished by the different levels: variables that were in the vignettes themselves and variables that represent the characteristics of the managers who evaluated the vignettes.

\section{Analyses}

Our vignette data have a hierarchical structure by design, observations are therefore not independent (Wallander, 2009). Multilevel analysis was used to deal with the hierarchical structure of the data (Hox, 2010). Multilevel models were estimated using two levels: (1) variables at the level of managers (managers' expectations of demotion, beliefs about productivity of older workers, and some background characteristics); and (2) variables regarding the items in the vignettes. In the analyses we control for age and sex of the manager, and whether the manager is also the owner of the firm in which he or she works.

\footnotetext{
${ }^{2}$ We carried out a confirmatory factor analysis in order to examine the construct validity of the two stereotype dimensions. The results show that items were all significantly loaded on their respective latent factors. The information criteria for the two factor model were also obtained (AIC=6067.8; $\mathrm{BIC}=6187.9$; RMSEA=0.087). An alternative one-factor model was also specified by loading all items on the same latent factor (AIC=6140.7; $\mathrm{BIC}=62.56 .9$; RMSEA=0.116). All three information criteria indicated a better fit for the two factor model.
} 


\section{Explaining demotion}

Before we present the results of the multilevel models to explain the attitudes of managers toward demotion in the cases of individual workers, we first present the general expectations of managers about the organizational consequences of introducing demotion as an instrument of HR policy.

Figure 2: Average expected consequences of demotion by Dutch managers, ranked by potentially negative effects of demotion becoming standard practice within the firm

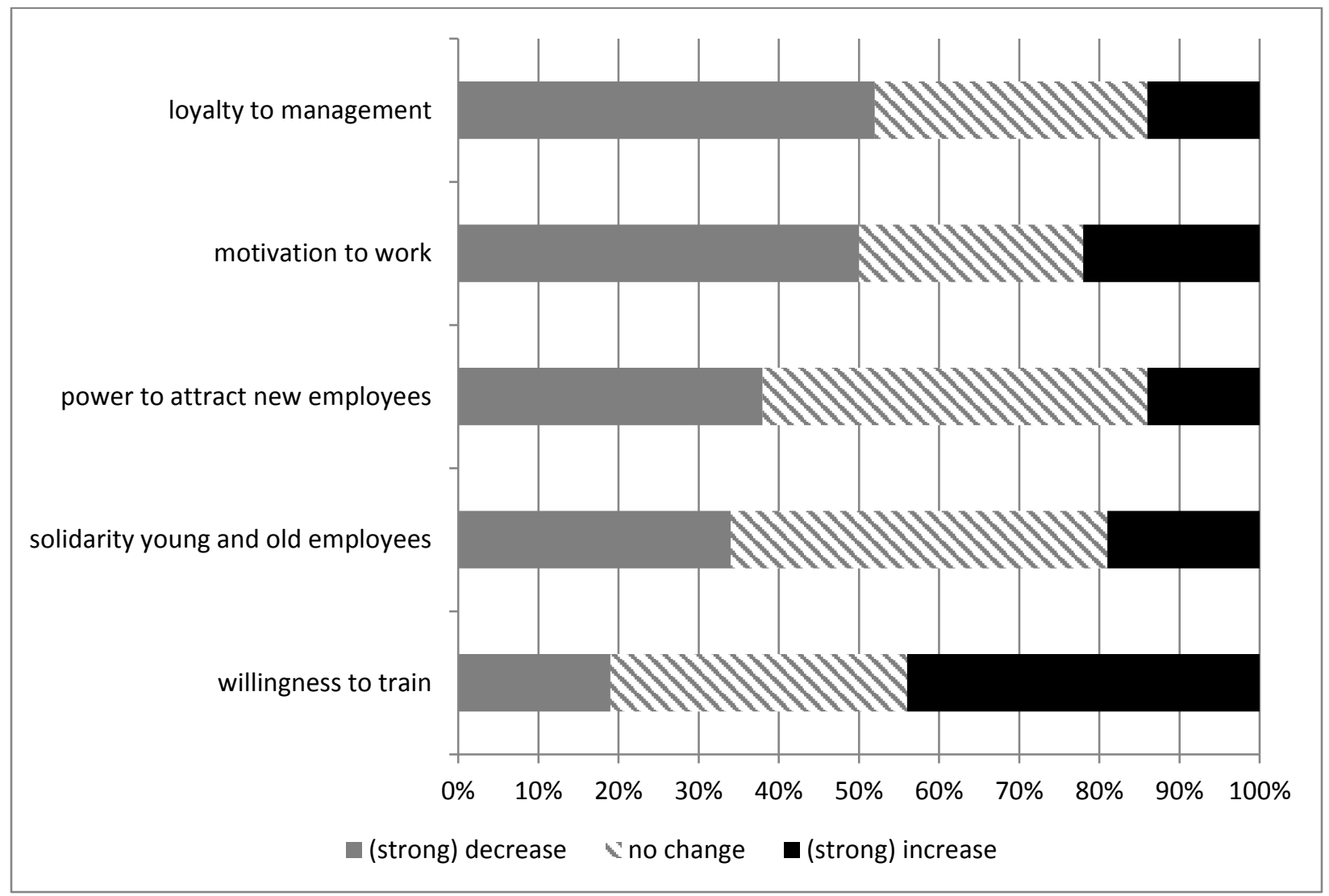

$\mathrm{N}=355$

Source: LISS data, April 2013

Figure 2 shows to what extent managers expect an increase or decrease in a number of domains of the organization as a result of introducing demotion into policy. The figure shows that a majority of managers expect a decrease in the loyalty of employees towards management and of work motivation as a result of introducing demotion. At the same time managers expect 
employees' willingness to undergo training to increase when demotion is introduced. With respect to the solidarity between younger and older workers and the ability of the firm to attract new employees, expectations are more varied with some managers expected that these aspects would be affected negatively by the introduction of demotion and some managers expected there would be no change in these factors.

To explain how managers evaluate particular cases of older workers who perform poorly, three models are estimated (see Table 3). Model I focuses on the vignette items, and these items mostly refer to the individual worker being evaluated. Model II incorporates the characteristics of the manager (in which their expected externalities are the focus of attention). Finally, model III is an alternative version of model II in which we check for non-linear externality effects. The dependent variable - the fairness of demotion for a specific older worker - is based on a scale from 0 to 10, hence all the (unstandardized) coefficients can be interpreted as adding or subtracting points to the base evaluation (the constant in the various models). The intra-class correlation across the models varies from 0.42 (model III) to 0.47 (model I). If we focus on model III, then one can say that $42 \%$ of the variance in evaluations is due to differences between managers and $58 \%$ is attributable to individual differences (within a manager who makes five evaluations).

The estimation results of model I provide strong support for the attribution hypothesis (H1), which predicts that poor performance attributed to factors that lie primarily beyond the control of the individual employee (such as age, health or problems at home), have a much lower impact on preferences for demotion than controllable factors such as a lack of motivation to work or a resistance to training. These two factors are the most important in explaining demotion, with coefficients 1.03 and 0.61 respectively. An employee with a poor health status is more likely to be considered for demotion than someone who is in good health, but the effect is rather limited (coefficient $=0.17$ ). Problems at home proved not to be significant. Another uncontrollable factor that did not affect managers' evaluations was the age of the older worker concerned. A priori, one would not expect age to influence the decision to demote because it is a character trait that is by definition not under the volitional control of an employee. Of course, it could be the case that managers have stereotypical views about the role played by age in causing 
a deterioration of performance. The regression results suggest that managers do not consider the age of an employee when assessing the fairness of the demotion of that specific older employee.

Table 3: Multilevel analysis of vignette experiments with respect to whether demotion is a fair decision (unstandardized coefficients)

\begin{tabular}{|c|c|c|c|c|c|c|}
\hline \multirow{3}{*}{$\begin{array}{l}\text { Vignette items } \\
\text { Characteristics of employee }\end{array}$} & \multicolumn{6}{|c|}{ Preference for demotion ${ }^{a}$} \\
\hline & \multicolumn{2}{|c|}{ Model I } & \multicolumn{2}{|c|}{ Model II } & \multicolumn{2}{|c|}{ Model III } \\
\hline & Coeff. & s.e. & Coeff. & s.e. & Coeff. & s.e. \\
\hline \multicolumn{7}{|l|}{ Work Motivation (high=0) } \\
\hline Low & $1.03 * *$ & 0.08 & $1.04 * *$ & 0.08 & $1.04 * *$ & 0.08 \\
\hline \multicolumn{7}{|l|}{ Willingness to train $($ high $=0$ ) } \\
\hline Low & $0.61 * *$ & 0.08 & $0.60 * *$ & 0.08 & $0.60 * *$ & 0.08 \\
\hline \multicolumn{7}{|l|}{ Age $(45$ years $=0)$} \\
\hline 50 years & -0.05 & 0.11 & -0.06 & 0.11 & -0.05 & 0.11 \\
\hline 55 years & -0.11 & 0.11 & -0.12 & 0.11 & -0.11 & 0.11 \\
\hline 60 years & -0.08 & 0.11 & -0.08 & 0.11 & -0.08 & 0.11 \\
\hline \multicolumn{7}{|l|}{ Health (healthy $=0$ ) } \\
\hline Not so healthy & $0.17 *$ & 0.08 & $0.16^{*}$ & 0.08 & $0.16^{*}$ & 0.08 \\
\hline \multicolumn{7}{|l|}{ Problems at home $($ no $=0)$} \\
\hline Yes & -0.06 & 0.08 & -0.06 & 0.08 & -0.06 & 0.08 \\
\hline \multicolumn{7}{|l|}{$\begin{array}{l}\text { Wage level compared to colleagues with } \\
\text { same function (lower }=0 \text { ) }\end{array}$} \\
\hline Higher & $1.08 * *$ & 0.08 & $1.07 * *$ & 0.08 & $1.07 * *$ & 0.08 \\
\hline \multicolumn{7}{|l|}{ Firm characteristic } \\
\hline \multicolumn{7}{|l|}{ Financial position firm (sound = 0) } \\
\hline Vulnerable & $0.23 * *$ & 0.09 & $0.23 * *$ & 0.09 & $0.23 * *$ & 0.09 \\
\hline In financial trouble & $0.25 * *$ & 0.10 & $0.26 * *$ & 0.10 & $0.26 * *$ & 0.10 \\
\hline \multicolumn{7}{|l|}{ Characteristics of manager } \\
\hline Age & - & - & 0.01 & 0.01 & 0.01 & 0.01 \\
\hline Sex $($ male $=0)$ & - & - & 0.19 & 0.16 & 0.18 & 0.16 \\
\hline Owner-manager & - & - & $0.59 *$ & 0.24 & $0.58 *$ & 0.24 \\
\hline Perception soft skills older workers & - & - & 0.15 & 0.20 & 0.17 & 0.20 \\
\hline Perception hard skills older workers & - & - & $-0.65 * *$ & 0.22 & $-0.64 * *$ & 0.22 \\
\hline Expected externalities & - & - & $-0.70 * *$ & 0.11 & 0.82 & 0.75 \\
\hline Expected externalities squared & - & - & - & - & $-0.22 *$ & 0.11 \\
\hline Constant & $3.26 * *$ & 0.15 & $5.66 * *$ & 0.70 & $3.19 * *$ & 1.41 \\
\hline S.d. (manager) & $1.39 * *$ & 0.06 & $1.25 * *$ & 0.06 & $1.27 * *$ & 0.06 \\
\hline S.d. $($ residual) & $1.48 * *$ & 0.03 & $1.48 * *$ & 0.03 & $1.48 * *$ & 0.03 \\
\hline Intra-class correlation & \multicolumn{2}{|c|}{0.47} & \multicolumn{2}{|c|}{0.43} & \multicolumn{2}{|c|}{0.42} \\
\hline Log Likelihood & \multicolumn{2}{|c|}{-3510.5} & \multicolumn{2}{|c|}{-3482.1} & \multicolumn{2}{|c|}{-3480.0} \\
\hline Wald Chi2 (df) & \multicolumn{2}{|c|}{$439.9(\mathrm{df}=10)$} & \multicolumn{2}{|c|}{$503.3(\mathrm{df}=16)$} & \multicolumn{2}{|c|}{$508.2(\mathrm{df}=17)$} \\
\hline $\mathbf{N}=$ & \multicolumn{2}{|c|}{1775} & \multicolumn{2}{|c|}{1775} & \multicolumn{2}{|c|}{1775} \\
\hline
\end{tabular}

(a) The preference for demotion is the answer given to the question: "To what extent would you find a demotion in this particular case fair?" (0) very unreasonable to (10) very reasonable. 
The vignette items that were introduced to offer context to the decision making process are noteworthy and warrant some comments also. First, the financial position of the firm in which the manager works is a contextual issue which managers might take into consideration. As it turns out, the financial position of the firm is of limited importance when managers assess the fairness of demotion. Compared to managers working for organizations in sound financial positions, those managers who work in financially vulnerable organizations are only slightly more supportive of demotion (coefficient $=0.23$ ). Second, the results show that the relative pay of a worker being considered for demotion turns out to be quite significant. For a worker who has a relatively high wage compared to his or her colleagues in a similar job the likelihood of demotion is substantially higher (coefficient $=1.08$ ).

In Model II we test the organizational externalities hypothesis $(\mathrm{H} 2)$, which predicts that the way in which the manager perceives the externalities of demotion policies is important to understanding their preference for demotion. The results provide clear evidence that if managers expect the consequences of demotion to be negative they are much less likely to prefer demotion of an individual worker compared to when the externalities of demotion are perceived to be modest.

Model II also provides support for the hypothesis H3 that the stereotypical views of managers toward older workers are relevant when explaining preferences about demotion. Managers who have more positive views about the hard skills of older workers are considerably less likely to support demotion. We do not find a statistically significant effect of managers' ratings of the soft skills of older workers. This finding suggests that managers weigh hard skills more strongly than soft skills when making judgments about demotion.

The estimation results reveal that both sets of factors - employee characteristics and manager characteristics - are highly complementary. All the coefficients on the vignette characteristics remain virtually unchanged when the perceived externalities and stereotypical beliefs about older workers are incorporated into our model. In other words, both sets of factors vignette items and manager characteristics - prove to be highly important and independent forces in explaining the assessed fairness of demotion. As such our estimation results provide strong support for all three hypotheses guiding this investigation. We also checked for the presence of 
interaction effects between the perceived externalities and attributed causes, but none appeared to be of significant influence on assessments of particular candidates.

\section{Figure 3: Effects of externalities in assessing the fairness of demotion}

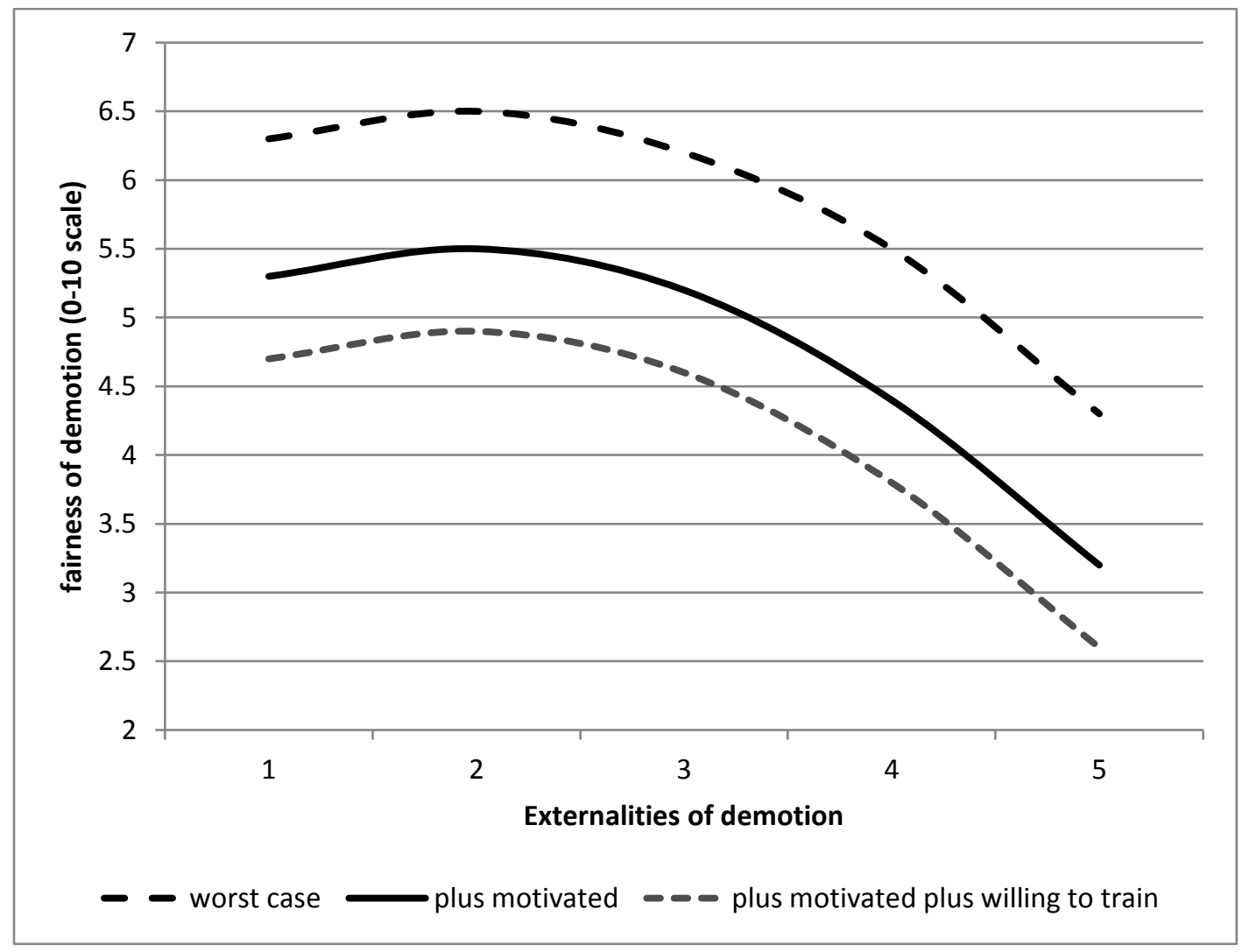

Externality scale of demotion is a 5-point scale where 1 denotes expected positive effects of demotion for the organization at large; 3 denotes a neutral position, and 5 denotes expected negative effects.

Source: LISS data, April 2013

In model III we test for possible non-linear effects of externalities on the demotion decision by adding a squared term to model II. The results reveal that including a squared term improves the model fit significantly $(\mathrm{Chi} 2=4.5 ; \mathrm{df}=1)$ and shows that the impact of the perceived externalities on demotion is asymmetrically assessed as negative externalities are more heavily weighed compared to positive externalities. The impact of the hypothesized effects of attributions and externalities on demotion scores are illustrated in Figure 3, in which the predicted preferences for demotion are depicted by the expected externalities for three individual 
cases of poorly performing employees. These calculations are based on the estimation presented in model III of Table 3. In Figure 3 three lines are shown where preferences for demotion are presented for three different hypothetical employees aged 45 years, with an income higher than colleagues in a similar job and in a financially sound organization. The upper dotted line (worst case) gives the estimated preferences for demotion for a poorly performing employee whose work motivation and willingness to participate in training is low. The other attributes of this employee also support the likelihood of poor performance, in that they are in poor health and have problems at home. The second (thick) line gives the estimated scores for a poorly performing employee with similar characteristics, but who has a high work motivation. The lower line depicts the scores for an employee who is motivated and also highly willing to be trained. The perceived externalities are shown on the horizontal axis. In judging whether a candidate is suitable for demotion we would expect the total evaluation to generate an evaluation grade that substantially exceeds the value 5 . Around the value 5 the manager is indifferent and substantially below 5 suggests that managers do not regard demotion as a reasonable measure to take. The figure shows clearly that demotion is a real option only in worst-case scenarios where an employee performs poorly and this can be attributed to controllable causes. Even in worstcase scenarios demotion is likely only if the manager expects no adverse consequences for the wider organization, however. If a manager expects negative externalities to occur from the introduction of demotion policies, support for demotion drops rapidly.

\section{Conclusions and discussion}

Demotion is seen by European employers as a possible policy option to address the challenges of an ageing work force but until now it has rarely been applied. Understanding why employers do not apply demotion on a wide scale is therefore of substantial interest, for both practice and theory. In this paper we have studied managers' decisions about demotion of older workers.

First, the study shows that managers are much more likely to consider demotion when they attribute the cause of poor performance to elements that are under the control of the employee under review. Managers are particularly vigilant about employees' work motivation and willingness to undertake training. Elements that lie outside the direct control of the individual, such as age, health, or the financial situation of the firm have little influence on decision-making about demotion. By doing so we extend the body of attribution theory. 
Demotion receives little attention in the human resource management literature. Current thinking about demotion is primarily inspired by labor economics (Baker et al., 1994) and personnel economics (Lazear, 1995), but even in those sub-disciplines demotion remains a side issue. By incorporating a psychological perspective on human decision making on the context of demotion, we have been able to demonstrate how attributions of employee performance can have economic consequences in terms of manager-subordinate relationships. By doing so, this work extends the relevance of attribution theory to a timely issue in ageing societies.

Second, this study shows also that the expectations and beliefs of a manager play a substantial role in the decisions they make about individual cases of demotion. In this respect, this study enriches attribution theory by showing that it matters also who makes the judgement. This study shows that when considering demotion, managers take the possible wider organizational consequences into account. As long as a practice, like demotion, is very rare, the introduction of demotion will be seen as the breaking of a taboo. Such a structural break with standard practice may have far-reaching effects and the results of our study suggest that in the mind of the managers this is indeed the case. The expectations of the manager about what will happen in the organization at large once the manager makes demotion an integral part of the incentive structure has a strong impact on the likelihood of demotion for an individual older worker. Managers generally fear the adverse consequences of demotion for their own organization, including the possibility of dwindling motivation and loyalty to management. Only a minority of managers expected demotion to generate benefits once it becomes standard practice.

In addition to the perceived organizational externalities, it matters whether the manager in question has strong beliefs about the (hard) skills of older workers: the more convinced a manager is that an older worker is, for example, creative, flexible, resistant to stress or has new technological skills, the less likely it is that such a candidate will be considered for demotion.

\section{Limitations and extensions}

There are some limitations to our study. First, we have limited our attention to a limited number of elements that are related to poor performance to investigate whether managers make a distinction between controllable and uncontrollable factors associated with employees' task 
performance. Future work might encompass more dimensions of performance, including citizenship behaviours and counterproductive behaviours (Griffin, Neal and Parker (2007) and Rotundo and Sackett (2002))in the analysis of demotion preferences of managers. A related limitation of this research is that managers have assessed hypothetical situations based on a relatively small number of vignette items related to poor performance. In developing and designing vignettes one has to make a trade-off between attaining a realistic description of a situation or a case and the ability of the participant to process information. Future research might experiment with more refined and elaborated vignettes on demotion by building upon our key findings.

A second limitation is that in the current paper we have restricted our attention to older workers. Future research might also look at a broader age range of workers, to identify differences in the treatment of older and younger workers. In the current investigation we found that the age of the employee in the range of 45-60 years does not play a significant role in the assessment of the managers. However, the absence of any significant age effects does not imply that age does not matter in applying demotion. One can at best conclude that older workers are seen as a homogenous group when it comes to the issue of applying demotion. To get a better grip on the issue of age one would to include the full age range from young to old. Survey research by (Van Dalen et al., 2010a) suggests that employees notice differences in treatment of older and younger workers by the management of organizations when the task performance of employees is below standard. When young workers underperform they are laid off, whereas underperforming older workers are tolerated to stay on.

A third limitation is that we have considered the issue of demotion in one country, or more specifically in one culture. However, cultures differ across countries and these differences may affect the way employers and employees value monetary rewards and performance systems (Satow and Wang, 1994, Tung and Baumann, 2009, Baumann, Hamin and Yang, 2016). A crosscultural study might shed more light on how demotion is perceived by these agents and how the role of attribution might differ across countries and explain why, for instance, demotion is considered more acceptable in Japan than it is in the US.

A fourth limitation is that demotion is only one element of HR policies. Firms may have other options to help them manage the careers of older workers, and indeed this has been the 
focus of some recent research. Van Dalen, Henkens and Wang (2015) showed, on the basis of an extensive survey among European employers, that a typology of employer behaviour with respect to older workers can be constructed. Employers either 'recharge' older workers - by investing in them or offering accommodation policies - or they retire them. By focusing on just one policy instrument - demotion - one may neglect the inter-relationship with other policies inside an organization, and future work might explore this aspect in more depth to investigate how managers perceive demotion as either an exit option or as an accommodation policy.

\section{Practical implications for management}

The fact that the perceived negative organizational consequences of demotion are a major force that prevents managers from using demotion is - as far as we can see - a novel contribution which has far-reaching consequences both for understanding organizational behaviour and for the day-to-day practice of HR management. To focus on the latter, our findings suggest that one should not expect managers or employers to embrace demotion on a large scale. Concerns about the negative consequences of demotion are dominant and this seems in line with the warning of Carson and Carson (2007) who state the maxim "whenever possible, avoid the use of demotions" (p. 465). For HR practice this does not necessarily make demotion a useless policy instrument. The current paper has focused on a decision which employers make: a decision made by one party which the other party - the demotee - has to accept or challenge this decision in court. Demotion under such circumstances is not a transaction which is based on mutual voluntary agreement. This may not be the case when older workers voluntarily opt for demotion once they realise that they are not performing well, and moving down the job ladder may offer them an opportunity to find a new balance at the end of their careers. An exploratory study among older workers in the Netherlands showed that 60 percent of older workers could imagine that they would move to a lower rank in their organization and earn less during the remainder of their careers (van Dalen and Henkens, 2015). This suggests that demotion may be a viable HR policy, but only when it takes place on a voluntary basis.

What is perhaps more important for everyday practice is that this paper demonstrates that demotion is not an isolated HR decision of an employer, but instead a socially and economically embedded organizational one. As the sociologist William Goode (1967) once pointed out in trying to understand demotion: 'The protection of the inept is a group phenomenon.' This article 
shows that Goode's intuition was correct and that the feasibility of demoting a particular employee is not only evaluated against the background of the characteristics of this employee, but also in view of the broader consequences that might spread through the organization.

This finding may also touch upon far-reaching practical problems because most organizations will have to adjust to an aging work force and HR solutions of the past - like early retirement - will no longer suffice. To reiterate the problem stated by Goode (1967): the dilemma that faces firms is whether the protection of the inept is perceived to be more valuable than protecting the group from the inept. Apparently, most managers choose to protect the inept instead of protecting the group from the inept. An open question is, of course, how these preferences evolve once population ageing becomes more visible to employers or when (global) competition intensifies. There may come a time when protecting the inept becomes less valuable than protecting the group from the inept. When these times come the perceived externalities may no longer be perceived to be negative but positive. The post-world war experience of Japan shows that demotion can become a standard part of working careers by its incorporation into labour contracts to split careers into two parts (Clark and Ogawa, 1996, Clark and Ogawa, 1997, Casey, 2005). Over time, employers in Japan realized that lifetime employment with a firm was a useful instrument to attract young and skilled workers, but also an expensive HR strategy. The same may very well be happening in Europe now. The presence of seniority wage systems together with high levels of employment protection plays a dominant role in the European labour market and organizations are reconsidering how to reconcile an ageing work force with the current incentive structure.

The Japanese labour market offers, however, one end of the spectrum, where demotion is seen as a normal part of a working life. The opposite end of the spectrum may be found in Anglo-Saxon countries, such as the US, Australia, and the UK, which offer far less employment protection and where wages are more flexible than in continental European countries. The reason that demotion is rarely observed in those countries may be more straightforward, because when workers begin to underperform, they may either begin to earn less or they may be dismissed (or as MacLeod and Malcomson (1988) suggest: they will resign in order to maintain their reputation). In other words, the pay-productivity gap can be closed by means of market forces in Anglo-Saxon countries. This is less easily accomplished in many European countries, where 
employment protection is still high and wage structures rigid, so the adjustments made necessary by an ageing labour force must arise from within organizations. The burden of adjustment is shifted to HR management and the prominence of demotion in some form may be the outcome of this process of adaption.

\section{References}

Ambrose, M.L., Seabright, M.A. and Schminke, M. (2002), "Sabotage in the workplace: The role of organizational injustice," Organizational Behavior and Human Decision Processes, 89, 947-965. Andersen, T.M. (2012), "A flexicurity labour market in the great recession: the case of Denmark," De Economist, 160, 117-140.

Baker, G., Gibbs, M. and Holmstrom, B. (1994), "The internal economics of the firm: evidence from personnel data," The Quarterly Journal of Economics, 109, 881-919.

Bartel, A.P. (1994), "Productivity gains from the implementation of employee training programs," Industrial relations: a journal of economy and society, 33, 411-425.

Baumann, C., Hamin, H. and Yang, S.J. (2016), "Work ethic formed by pedagogical approach: evolution of institutional approach to education and competitiveness," Asia Pacific Business Review, 22, 374-396.

Black, S.E. and Lynch, L.M. (1996), "Human-capital investments and productivity," The American economic review, 86, 263-267.

Bloom, D.E., Boersch-Supan, A., McGee, P. and Seike, A. (2011), "Population aging: facts, challenges, and responses," Benefits and Compensation International, 41, 22.

Bosse, D.A., Phillips, R.A. and Harrison, J.S. (2009), "Stakeholders, reciprocity, and firm performance," Strategic Management Journal, 30, 447-456.

Bowlus, A.J. and Robin, J.-M. (2004), "Twenty years of rising inequality in US lifetime labour income values," The Review of Economic Studies, 71, 709-742.

Carson, P.P. and Carson, K.D. (2007), "Demystifying demotion: A look at the psychological and economic consequences on the demotee," Business Horizons, 50, 455-466.

Casey, B.H. (2005), "The employment of older people: can we learn from Japan?," Geneva Papers on Risk and Insurance. Issues and Practice, 620-637.

Cattin, P. and Wittink, D.R. (1982), "Commercial use of conjoint analysis: A survey," Journal of Marketing, 46.

Cerasoli, C.P., Nicklin, J.M. and Ford, M.T. (2014), "Intrinsic motivation and extrinsic incentives jointly predict performance: A 40-year meta-analysis," Psychological Bulletin, 140, 980.

Chui, W.C.K., Chan, A.W., Snape, E. and Redman, T. (2001), "Age, stereotypes and discriminatory attitudes towards older workers. An east-west comparison," Human Relations, 54, 629-661. Clark, R.L. and Ogawa, N. (1996), "Human resource policies and older workers in Japan," The Gerontologist, 36, 627-636.

Clark, R.L. and Ogawa, N. (1997), "Transitions from career jobs to retirement in Japan," Industrial Relations: A Journal of Economy and Society, 36, 255-270.

Conen, W.S., van Dalen, H.P. and Henkens, K. (2012), "Ageing and employers' perceptions of labour costs and productivity: A survey among European employers," International Journal of Manpower, 33, 629-647.

Cox, C.B. and Beier, M.E. (2014), "Too old to train or reprimand: The role of intergroup attribution bias in evaluating older workers," Journal of Business and Psychology, 29, 61-70.

Dedrick, E.J. and Dobbins, G.H. (1991), "The influence of subordinate age on managerial actions: An attributional analysis," Journal of organizational behavior, 12, 367-377. 
Deelen, A.P. (2012), "Wage-tenure profiles and mobility," De Economist, 160, 141-155.

Demerouti, E., Bakker, A.B. and Voydanoff, P. (2010), "Does home life interfere with or facilitate job performance?," European Journal of Work and Organizational Psychology, 19, 128-149.

Di Stasio, V. (2013), Why education matters to employers: a vignette study in Italy, England and the Netherlands, Amsterdam: University of Amsterdam.

Ederer, F. and Patacconi, A. (2010), "Interpersonal comparison, status and ambition in organizations," Journal of Economic Behavior \& Organization, 75, 348-363.

Erber, J.T. and Long, B.A. (2006), "Perceptions of forgetful and slow employees: Does age matter?," The Journals of Gerontology Series B: Psychological Sciences and Social Sciences, 61, P333-P339.

Finch, J. (1987), "The vignette technique in survey research," Sociology, 21, 105-114.

Finkelstein, L.M. and Burke, M.J. (1998), "Age stereotyping at work: the role of rater and contextual factors on evaluations of job applicants," Journal of General Psychology, 125, 317-345.

Gibbons, R. and Waldman, M. (1999), "A theory of wage and promotion dynamics inside firms," The Quarterly Journal of Economics, 114, 1321-1358.

Gibbs, M. and Hendricks, W. (2004), "Do formal salary systems really matter?," Industrial and Labor Relations Review, 71-93.

Gielen, A.C. and van Ours, J.C. (2006), "Age-specific cyclical effects in job reallocation and labor mobility," Labour Economics, 13, 493-504.

Goode, W.J. (1967), "The protection of the inept," American Sociological Review, 5-19.

Green, P.E. and Srinivasan, V. (1978), "Conjoint analysis in consumer research: issues and outlook," Journal of consumer research, 103-123.

Griffin, M.A., Neal, A. and Parker, S.K. (2007), "A new model of work role performance: Positive behavior in uncertain and interdependent contexts," Academy of Management Journal, 50, 327-347.

Harvey, N., Madison, K., Martinko, M., Crook, T. and Crook, T. (2014), "Attribution Theory in the Organizational Sciences: The Road Traveled and the Path Ahead," The Academy of Management Perspectives, amp. 2012.0175.

Henkens, K. and Schippers, J. (2012), "Active ageing in Europe: the role of organisations," International Journal of Manpower, 33, 604-611.

Hox, J. (2010), Multilevel analysis: Techniques and applications: Routledge.

Josten, E. and Schalk, R. (2010), "The effects of demotion on older and younger employees," Personnel Review, 39, 195-209.

Kapteyn, A., Smith, J.P. and Van Soest, A. (2007), "Vignettes and self-reports of work disability in the United States and the Netherlands," The American economic review, 461-473.

Kohl, J.P. and Stephens, D.B. (1990), "Is demotion a four-letter word?," Business Horizons, 33, 74-76.

Lazear, E.P. (1979), "Why is there mandatory retirement?," The Journal of Political Economy, 1261-1284.

Lazear, E.P. (1990), "Adjusting to an aging labor force," in Issues in the Economics of Aging: University of Chicago Press, 1990, pp. 287-316.

Lazear, E.P. (1995), Personnel economics (series): the MIT Press.

Lazear, E.P. (1998), Personnel economics for managers: Wiley New York.

Lee, J.A. and Clemons, T. (1985), "Factors affecting employment decisions about older workers," Journal of Applied Psychology, 70, 785-788.

Loretto, W., Duncan, C. and White, P.J. (2000), "Ageism and employment. Controversies, ambiguities and younger people's perceptions," Ageing \& Society, 20, 279-302.

MacLeod, W.B. and Malcomson, J.M. (1988), "Reputation and hierarchy in dynamic models of employment," Journal of Political Economy, 96, 832-854.

McCann, R. and Giles, H. (2003), "Ageism and the workplace. A communication perspective," in Ageism, stereotyping and prejudice against older persons, ed. T.D. Nelson, Cambridge MA: MIT Press, pp. 163199. 
Milgrom, P.R. and Roberts, J. (1992), Economics, organization and management: Prentice-Hall Englewood Cliffs, NJ.

Mitchell, T.R. and Wood, R.E. (1980), "Supervisor's responses to subordinate poor performance: A test of an attributional model," Organizational Behavior and Human Performance, 25, 123-138.

Munnell, A.H. and Sass, S.A. (2008), Working longer: The solution to the retirement income challenge: Brookings Inst Pr.

Ng, T.W.H. and Feldman, D.C. (2008), "The relationship of age to ten dimensions of job performance," Journal of Applied Psychology, 93, 392-423.

Nohe, C., Michel, A. and Sonntag, K. (2014), "Family-work conflict and job performance: A diary study of boundary conditions and mechanisms," Journal of Organizational Behavior, 35, 339-357.

OECD (2006), Live longer, work longer. A synthesis report, Paris: Organization for Economic Development.

OECD (2014), Ageing and Employment Policies: Netherlands 2014: OECD Publishing.

Posthuma, R.A. and Campion, M.A. (2009), "Age Stereotypes in the Workplace: Common Stereotypes, Moderators, and Future Research Directions ", Journal of Management, 35, 158-188.

Robinson, S.L. (1996), "Trust and breach of the psychological contract," Administrative science quarterly, 574-599.

Rossi, P.H. and Anderson, A.B. (1982a), "The factorial survey approach. An introduction," in Measuring Social Judgments. The factorial survey approach, eds. P.H. Rossi and S.L. Nock, Beverly Hills: Sage.

Rossi, P.H. and Anderson, A.B. (1982b), "The factorial survey approach: An introduction," Measuring social judgments: The factorial survey approach, 15-67.

Rotundo, M. and Sackett, P.R. (2002), "The relative importance of task, citizenship, and

counterproductive performance to global ratings of job performance: a policy-capturing approach," Journal of Applied Psychology, 87, 66.

Satow, T. and Wang, Z.-M. (1994), "Cultural and organizational factors in human resource management in China and Japan: A cross-cultural socio-economic perspective," Journal of Managerial Psychology, 9, 3-11.

Sauer, C., Auspurg, K., Hinz, T. and Liebig, S. (2011), "The application of factorial surveys in general population samples: The effects of respondent age and education on response times and response consistency," in Survey Research Methods, pp. 89-102.

Taylor, P. and Walker, A. (1998), "Employers and older workers: attitudes and employment practices," Ageing and Society, 18, 641-658.

Thurow, L.C. (1975), Generational Inequality, New York: Basic Books.

Tung, R.L. and Baumann, C. (2009), "Comparing the attitudes toward money, material possessions and savings of overseas Chinese vis-a-vis Chinese in China: convergence, divergence or cross-vergence, vis-avis 'one size fits all'human resource management policies and practices," The International Journal of Human Resource Management, 20, 2382-2401.

Van Dalen, H., Henkens, K. and Schippers, J. (2009a), "Unraveling the age-productivity nexus: Confronting perceptions of employers and employees," CentER Discussion Paper, 2009.

van Dalen, H.P. and Henkens, K. (2015), "Is demotie echt een taboe?: Oudere werknemers aan het woord," Me Judice.

Van Dalen, H.P., Henkens, K. and Schippers, J. (2010a), "How do employers cope with an ageing workforce? Views from employers and employees," Demographic Research, 22, 1015-1036.

Van Dalen, H.P., Henkens, K. and Schippers, J. (2010b), "Productivity of older workers: Perceptions of employers and employees," Population and Development Review, 36, 309-330.

Van Dalen, H.P., Henkens, K. and Schippers, J.J. (2009b), "Dealing with older workers in Europe: a comparative survey of employers' attitudes and actions," Journal of European Social Policy, 19, 47-60. 
Van Dalen, H.P., Henkens, K. and Wang, M. (2015), "Recharging or retiring older workers? Uncovering the age-based strategies of European employers," The Gerontologist, 55, 814-824.

Van den Heuvel, S.G., Geuskens, G.A., Hooftman, W.E., Koppes, L.L. and Van den Bossche, S.N. (2010), "Productivity loss at work; health-related and work-related factors," Journal of occupational rehabilitation, 20, 331-339.

Van Vianen, A.E., Dalhoeven, B.A. and De Pater, I.E. (2011), "Aging and training and development willingness: Employee and supervisor mindsets," Journal of Organizational Behavior, 32, 226-247.

Wallander, L. (2009), "25 years of factorial surveys in sociology: A review," Social Science Research, 38, 505-520.

Weiner, B. (1993), "On sin versus sickness: A theory of perceived responsibility and social motivation," American psychologist, 48, 957.

Weiner, B. (1995), Judgments of responsibility: A foundation for a theory of social conduct: Guilford Press.

Wood, R.E. and Mitchell, T.R. (1981), "Manager behavior in a social context: The impact of impression management on attributions and disciplinary actions," Organizational Behavior and Human Performance, 28, 356-378. 


\section{Appendix:}

\section{Figure 1A: Example of a vignette}

In the Netherlands more and more people are trying to place demotion - the lowering of rank and wages when employees show decreased performance - on the policy agenda. Below you will find a description of a number of older workers who for one reason or another show a strong decrease in performance.

Please indicate, for each profile, how fair it would be to consider demotion for the specific employee?

\begin{tabular}{|l|l|}
\hline Context & \\
\hline Financial position organization & Financially sound \\
\hline Applicant & \\
\hline Age (years) & 50 \\
\hline Work motivation & High \\
\hline Willingness to participate in training & Low \\
\hline Health & In good health \\
\hline Problems at home & Yes \\
\hline $\begin{array}{l}\text { Wage level in comparison to colleagues with } \\
\text { the same function }\end{array}$ & Higher than comparable colleagues \\
\hline
\end{tabular}

To what extent would you consider demotion in this specific case to be fair?

\begin{tabular}{ccccccccccc}
\hline 0 & 1 & 2 & 3 & 4 & 5 & 6 & 7 & 8 & 9 & 10 \\
\hline Very unfair & & & & & & & & & & \\
& & & & & & & & & & \\
\hline
\end{tabular}

